\title{
LETRADOS E ESCRITA DA HISTÓRIA ESCOLAR: SEBASTIÃO PARANÁ E O MANUAL O BRASIL E O PARANÁ PARA USO NAS ESCOLAS PRIMÁRIAS
}

Maria Aparecida Leopoldino*

RESUMO: O artigo apresenta resultados de pesquisa desenvolvida no campo da História da Disciplina Escolar. Nele, o texto do livro didático se apresenta como um elemento central para se compreender as estratégias de conformação de uma disciplina escolar que historicamente se articula com a organização curricular, com o lugar social de seu autor e as práticas pedagógicas instituídas na cultura escolar da sociedade brasileira. Toma como objeto de estudo e fonte de pesquisa o manual $O$ Brasil e o Paraná para uso nas escolas primárias, publicado ineditamente em 1903, pelo seu autor Sebastião Paraná (18641938), por meio da instituição paranaense Ginásio Paranaense e Escola Normal. O objetivo é perceber como o professor-autor dialoga com um campo de saber em construção que agrega sentido a uma "história regional" constituinte de um debate que, no calor dos ideais republicanos, associa a representação de nação com suas partes constituintes - os estados.

PALAVRAS-CHAVE: História da Disciplina. Ensino de História Escolar. Sebastião Paraná. Manuais Escolares.

ABSTRACT: The article presents research results from the History of School Discipline. In it, the texto the textbook is

* Professora de Didática e Metodologia do Ensino de História, Departamento de Teoria e Prática da Educação, da Universidade Estadual de Maringá (UEM). Doutora em Educação pelo Programa História, Política, Sociedade da Pontifícia Universidade Católica de São Paulo. 
presented as a central element for understand in the forming strategies of school discipline that historicall y articulated with the curricular organization with the social position of its author and the pedagogical practices instituted in thes chool culture Brazilian society. It takes as objecto studyandre search sourcethe manual "Brazil and Paraná for use in primary schools", um precedentedly published in 1903 by its author Sebastian Paraná (1864-1938), through the Paraná institution Gym Paranaense and Normal School. The understand how the teacher-author converses with in construction that a "regional history" constituent of a debate that in the heat of republicanideals, associates the nation of representation with its constituent parts - the United.

KEYWORDS: History of her Discipline. School History Teaching. Sebastião Paraná. Librostext.

\section{Introdução}

Não se celebra mais a nação, mas se estudam suas celebrações. (NORA, 1993, p. 14).

Editado em 1903 pela Empreza Graphica Paranaense, o manual intitulado O Brasil e o Paraná para uso nas escolas primárias $^{1}$, de autoria do intelectual Sebastião Paraná de Sá Sottomar (1864-1938), foi considerado pela comissão que o aprovou, naquele mesmo ano, como capaz de cumprir "a missão cívica" de apresentar o "Estado do Paraná aos futuros professores do ensino primário". Muito elogiado pelos catedráticos do então Ginásio Paranaense e Escola Normal de Curitiba, o livro contribuiu para a criação de uma memória sobre o passado paranaense. Por

1 A edição utilizada neste trabalho é a $19^{\mathrm{a}}$ edição: PARANÁ, Sebastião. O Brasil e o Paraná: para uso das escolas primárias. 19. ed. melhorada. Curitiba: Empreza Graphica Paranaense, 1929. 
seu intermédio, elaborou-se uma tradição discursiva da Geografia e da História do Paraná nas décadas iniciais da República que, pelas inúmeras reimpressões que recebeu - $22^{a}$ edição em 1941 -, sugere o quanto suas ideias estavam em sintonia com os conhecimentos considerados socialmente necessários à época.

Professor catedrático de Geografia e Corografia do Brasil, desde 18 de abril de 1900, Sebastião Paraná regeu também, a partir de 1906, a cadeira de História Universal na mesma instituição. Nascido em Curitiba, realizou seus estudos preparatórios na Província e, em 1883, seguiu para o Rio de Janeiro, onde se diplomou em Ciências Jurídicas e Sociais pela Faculdade de Direito. Homem público, de volta à terra natal, traçou sua vida vinculando-se ao universo dos letrados, atuando como político e, mais especificamente, no meio educacional. Além de catedrático da principal instituição de ensino secundário do Paraná à época, foi também diretor do Museu Paranaense e Biblioteca Pública do Paraná; em 1916, exerceu a Superintendência Geral do Ensino do estado; chegou a ser diretor do Ginásio Paranaense em 1920; e professor da Universidade Federal do Paraná.

Quando da aprovação de seu manual pela Congregação do Ginásio Paranaense e Escola Normal, Sebastião Paraná ocupava uma cadeira no Congresso Legislativo como deputado e outra como membro do Conselho Superior do Ensino Público do estado. Além de estar envolvido com a escola primária e o ensino secundário, ele se encontrava atuante como membro de diversos Institutos Históricos e Geográficos do país, além do Instituto Histórico e Geográfico Paranaense. Situação que o posicionou em meio aos debates que envolviam a escrita da história e o papel da geografia para explicar a nacionalidade brasileira.

Com os conhecimentos da História Universal recebidos na formação humanística que caracterizou os seus estudos, preocupou-se com a Geografia e a História do estado, tendo por terreno teórico os saberes históricos comprometidos com os destinos da nação e a formação de cidadãos fiéis à Pátria. $A$ "causa educacional" o ocupou ao longo de sua vida, foi o lugar social de onde tomou suas decisões profissionais e chegou à 
compreensão do seu papel frente à ruptura política com o passado nacional e os problemas a serem enfrentados no tempo presente.

Pertencente ao diminuto mundo letrado, Sebastião Paraná gozava de prestigio junto às instituições culturais, o que possibilitou sua atuação na pesquisa e no ensino para definir o discurso histórico do espaço regional, temática que mobilizou não apenas o universo econômico e político, mas também o simbólico-cultural, diante da meta dos republicanos de expansão da urbanização e, nela, de escolarização da sociedade paranaense.

Ao tratar do seu manual, este trabalho considera que o livro escolar não é algo abstrato e com sentido em si mesmo, mas consiste em um objeto cultural próprio da sociedade escolarizada, vinculado à cultura escolar que lhe dá sentido e legitimidade. A escrita de Sebastião Paraná tem, portanto, a marca de sua historicidade e suas condições socioculturais de produção, circulação e usos sociais. Situado desse modo, o livro e seu autor são compreendidos em meio às atividades da instituição educativa a que se vinculava, mas também relacionados com as demais instituições culturais que lhes deram sustentação e existência².

Entende-se, por essas razões, que o manual escolar sinaliza para a problemática do processo de constituição de um saber disciplinar regional no qual estariam envolvidos sujeitos, instituições, políticas governamentais, práticas e lugares sociais nos quais os conteúdos disciplinares foram discutidos, aceitos ou rejeitados, produzidos e publicados para o ensino. Os livros escolares, quando interrogados, permitem abordar as tramas relacionais de uma época, uma vez que se ligam à maneira de determinado grupo social significar o difuso passado ao qual se referem, por meio de sua narrativa e organização textual.

2 As condições socioculturais estão pensadas conforme indica Chartier (1990). Ou seja, identificadas no "modo como em diferentes lugares e momentos uma determinada realidade social é construída, pensada, dada a ler" (CHARTIER, 1990 , p. 16-17). Nesse sentido, debruça-se sobre os esquemas intelectuais, a narrativa, que orientam a apreensão do universo pelo autor e sobre "as figuras graças às quais o presente pode adquirir sentido, o outro tornar-se inteligível e o espaço ser decifrado" (CHARTIER, 1990, p. 17). 
Tomar o livro de Sebastião Paraná como fonte possibilita visualizar tais dimensões e, ao mesmo tempo, reconhecer que o texto didático está envolvido num movimento complexo das relações internas e externas ao espaço educacional que se liga, entre outros, ao processo de urbanização do estado no início da República. Em sua elaboração, observa-se a estreita relação estabelecida entre a política republicana para o ensino, a ampliação de editoração de impressos, das estruturas escolares, bibliotecas, livrarias e a organização de espaços de sociabilidades entre os letrados que estavam imersos nas discussões sobre a nação republicana.

Nesse contexto é que a produção didática recebeu um lugar específico no amplo processo histórico e cultural da sociedade paranaense. Tal manifestação oficial de produção de saberes sobre o passado nacional e regional precisa ser estudada, detalhando os sentidos de seu discurso, o significado de progresso e de modernização destinado para a sociedade no período.

Entre os atores que estão envolvidos com a produção do manual, neste artigo, ressalta-se o autor e sua obra no contexto de sua elaboração. Sobre o período em análise, Circe Bitencourt (2004), ao tratar da produção didática brasileira no período que vai de 1810 a 1910, indica, nessa longa temporalidade, que, por volta de 1827, é possível identificar autores preocupados com o ensino primário e "esboçando algumas contribuições para o ensino de primeiras letras". Foi apenas a partir dos anos de 1880 que se tornou possível criar uma "literatura que, sem abandonar o secundário, dedicaram-se à constituição do saber da escola elementar" (BITTENCOURT, 2004, p. 480). De maneira que só no final do século XIX e no século XX é que se verifica a ampliação de letrados dispostos a publicar livros para as escolas primárias.

No caso deste trabalho, o objetivo é perceber como o professor-autor dialoga com um campo de saber escolar em construção, que agrega sentido a uma "história regional" constituinte de um debate que, no calor dos ideais republicanos, associa a representação de nação com suas partes constituintes - os estados. Afirma-se, portanto, o caráter criativo dos sujeitos ao 
produzirem fundamentos políticos e pedagógicos para a disciplina escolar no processo de seleção, organização e didatização de saberes figurados como socialmente necessários (CHERVEL, 1990).

Para tratar desses aspectos do manual, o texto foi dividido em três momentos. Inicialmente, entendeu-se importante dar visibilidade ao lugar institucional a que Sebastião Paraná estava vinculado, quando da produção e da aceitação do seu escrito. Na sequência, apresentou-se a narrativa construída sobre o Paraná em sua relação com a produção de um conceito de região tal como foi pensada na época, como partícipe de progresso e de modernidade. Nas considerações finais, observou-se como o projeto político, em que o manual exerceu um importante papel na construção de saberes escolares, possibilitou que o autor representasse o espaço e configurasse um campo disciplinar para ensinar História e Geografia no ensino primário, ou seja, para os anos iniciais do ensino fundamental tal como conhecemos atualmente.

\section{Letrados e ensino: Sebastião Paraná e o lugar institucional}

Em 1903, na sede do Gymnasio Paranaense, a comissão ${ }^{3}$ designada para avaliar o livro de Sebastião Paraná - Emiliano Perneta, Chichorro Junior, Dario Vellozo - publica o seguinte parecer:

Cidadão Dr. Victor Ferreira do Amaral, D.D. Director da Instrucção Publica do Paraná. A comissão abaixo assignada, por vós nomeada para dar parecer sobre o livro do Dr. Sebastião Paraná - O Brasil e o Paraná - escripto PARA USO DAS ESCOLAS PRIMARIAS, - tendo

3 Por intermédio da Congregação do Ginásio, os catedráticos tomavam decisões sobre a organização pedagógica e o desenvolvimento das ações administrativas da instituição. Era o conselho deliberativo sobre a adoção de livros didáticos e sobre a emissão de pareceres a respeito de obras didáticas encaminhadas para avaliação por meio de uma comissão de professores. 
estudado convenientemente o trabalho do ilustre collega, entende que o referido livro preenche com brilho os fins a que se propoz o autor, devendo ser adoptado nas escolas publicas do Estado.

Escripto com amor pela terra natal - O Brasil e o Paraná - põe em bello relevo, não só a Patria Brasileira, senão tambem, e principalmente, este radioso Estado, digno de ser conhecido, para que realize desde logo o bello destino para que o fadou a Natureza. É conhecendo o berço que o homem aprende a amal-o. O Brasil e o Paraná ensina-o sufficientemente, offerecendo rutilante exemplo, communicativo, de veneração e civismo.

Coritiba, 1 de Outubro de 1903. (PARANÁ, 1929, p. 3).

Ao se eleger o livro de Sebastião Paraná como capaz de cumprir a missão cívica de apresentar o estado para a comunidade escolar, parte dos letrados - naquele momento representada por Emiliano Perneta, Chichorro Junior e Dario Vellozo - encontravase na direção de um projeto político e cultural de empreendimento patriótico que incorporou no debate, presente desde a década de 1870, a instituição educacional.

A percepção do lugar social de produção do manual de Sebastião Paraná permite visualizar a vinculação entre os letrados próximos ao poder político e os autores das obras destinadas à divulgação de saberes para instituições escolares. Do conjunto de membros que compunham a Congregação, sobressaia um núcleo de intelectuais constituído de indivíduos, em geral de origens e laços sociais privilegiados, que participavam ativamente da produção de conhecimentos literários e científicos e que, em fins do século XIX e início do XX, buscavam também uma representação discursiva e simbólica de região, diante dos desafios de caracterizar o território nacional.

Tratava-se de empreender um conhecimento sobre a nação que pudesse ser qualificado como uma "grande obra nacional" que, na sua divulgação, propagasse as "glórias" regionais fazendo-as disponíveis não apenas para o círculo de letrados, mas a um maior número de pessoas possível, de modo a ser capaz de produzir um discurso sobre identidades - nacional e 
regional. Para alcançar tal intento, foram mobilizados esforços e competências dos intelectuais envolvidos com o objetivo de produzir tais conhecimentos sobre a realidade social. O esforço passava também pela elaboração e publicação dos escritos para uso nas instituições educacionais na forma de livros escolares.

Envolvido com tais questões estava Sebastião Paraná, que, filho e neto de militar $^{4}$, diplomado em Direito no município da Corte, foi influente na produção de ideais que reforçavam a grandiosidade nacional e a situação do estado diante da esperança, que a elite sustentava, de um futuro promissor em direção à "civilização". Atuante nas questões educacionais, Sebastião escreveu vários livros que pudessem expressar seus anseios patrióticos: Espaço geográfico do Paraná (1889); Chorografia do Paraná (1899); O Brasil e o Paraná para escolas primárias (1903); Os estados da República (1911); Paizes da América (1922); Galeria Paranaense (1922); Paizes da Europa (1926); Efemérides da Revolução de Outubro de 1930 no estado do Paraná (1931).

Envolvido com as atividades das instituições governamentais, o bacharel estava enredado nos debates que tratavam de pensar sobre a escrita da história e o papel da geografia para compreender a região, seja na fixação do objeto da Geografia, seja na produção de uma narrativa histórica sobre o Paraná. De maneira que, além de catedrático do Gymnasio Parananese e da Escola Normal, Sebastião Paraná também estava vinculado como sócio correspondente do Instituto Histórico e Geográfico Brasileiro $^{5}$, de vários institutos regionais (Instituto Histórico e Geográfico Parahybano; Instituto Arqueológico e Geográfico Alagoano; Instituto Histórico e Geográfico de Sergipe; Instituto Histórico e Geográfico de São Paulo; Instituto Histórico e Geográfico Catarinense) e, ainda, ao Instituto Geográfico Argentino e à Sociedade Geográfica de Lisboa ${ }^{6}$.

4 Filho do Capitão Inácio de Sá Sottomaior e neto do Coronel de milícias do mesmo nome.

5 Sobre o IHGB, ver Guimarães (1988).

6 E mais: da Sociedade de Geografia do Rio de Janeiro; sócio efetivo do Centro 
Suas referências institucionais indicam que em seus contatos estavam, além dos diversos institutos históricos e geográficos do país, grandes centros internacionais do universo científico, como a Sociedade Geográfica de Lisboa. Em um momento no qual as fronteiras dos conhecimentos científicos ainda não estavam plenamente definidas, seus vínculos sugerem, ainda, o campo que estava inclinado a seguir e o interesse que tinha na tarefa do IHGP, de "coligir, estudar, publicar e arquivar os documentos que sirvam à historiografia do Paraná, promovendo a difusão de seu conhecimento pela imprensa e pela tribuna" (BIHGP, 1917, p. 22).

A inserção de Sebastião Paraná nas questões de seu tempo se realizou, portanto, por meio de seu desempenho, amplamente reconhecido, nas funções públicas realizadas em prol das causas educacionais. É significativo, nesse aspecto, o registro de que seu manual foi premiado com medalha de prata pelo Jury Superior da Exposição Nacional em 1908.

Considerando a temporalidade da sua escrita, as informações por ele utilizadas na construção de sua narrativa foram oriundas de trabalhos de cronistas, narrativas de viajantes e de textos divulgados pelo Instituto Histórico e Geográfico Brasileiro que circulavam entre os letrados à época ${ }^{7}$. A apropriação que fez dessas fontes ganhou corpo e força num cenário em que a instituição de ensino paranaense alimentava discussões acerca da construção da ideia de progresso, de modernidade, e ainda, de identidade regional, para inaugurar uma ideia de nação, de povo e de liberdade no cenário republicano.

Em um contexto de maior circulação de ideias, a criação da imprensa paranaense ${ }^{8}$ ampliou o universo de leitores e as

de Letras do Paraná e da Academia de Letras do Paraná (PARANÁ, 1929, p. 2).

7 É importante dizer que a obra de Romário Martins, História do Paraná, publicada em 1899, circulava entre os intelectuais. Nela, Martins propunha uma descrição dos seguintes aspectos: "meio físico"; "distribuição geográfica das tribos indígenas"; "fatores étnicos fundamentais". Ver: MARTINS, Romário. História do Paraná. Curitiba: Travessa dos Editores, 1995, p. 3, 4.

8 Com a criação da "Impressora Paranaense", em 1888, sob a gerência de 
atividades dos intelectuais que estavam envolvidos com a tarefa de escrever para os jornais e revistas locais, de participar de clubes literários e exercer o magistério. Tais círculos sociais eram importantes locais para divulgar suas ideias, discutir, opinar, criticar e sugerir projetos de futuro para a sociedade. Nesses espaços, discutiam com adversários e enalteciam seus colaboradores, bem como reivindicavam apoio aos seus projetos.

Imerso nesses espaços de sociabilidade, Sebastião Paraná convivia com grupos letrados em um cenário político no qual a escola primária tornava-se o centro irradiador dos saberes necessários a todos os cidadãos de uma república livre. $O$ aumento da produção didática para a escola primária se inseria nessa conjuntura em que os conhecimentos de História, Geografia e Língua Portuguesa passavam a exercer um papel importante na consolidação do projeto educativo de difusão do patriotismo. Na mesma medida em que o discurso institucional enfatizava a elaboração de manuais e cartilhas escolares como uma missão patriótica.

Boguszewski (2007) observa que o número de estabelecimentos gráficos se multiplicou em Curitiba nas duas primeiras décadas do século $X X$. O resultado dessas estratégias editoriais foi a ampliação das possibilidades de divulgar textos impressos e sua disponibilização para um maior número de leitores urbanos. Uma realidade editorial que atingiu também a editoração dos livros escolares e possibilitou a expansão do ensino primário para a população até então sem acesso à escola elementar.

Denominada de Ginásio Paranaense e Escola Normal, no tempo republicano, a instituição tornou-se, no contexto paranaense, um lugar social de produção dos conhecimentos necessários não apenas para a formação das elites locais que se preparavam para ingressar nos cursos superiores, mas igualmente para a formação de professores das escolas primárias. Criada

Jesuíno Lopes, a qualidade técnica de que ela dispunha possibilitou a profissionalização da arte gráfica no Paraná e a ampliação ao acesso da população letrada ao impresso em geral e ao livro em especial. 
no século XIX como Liceu, foi por muito tempo apenas uma instituição de ensino secundário, por vezes funcionando com poucas aulas destinadas aos cursos preparatórios. Na década de 1870, tornou-se Instituto de Preparatórios e recebeu a tarefa de incorporar uma Escola Normal para formar professores do ensino elementar (TOLEDO, 2005).

A existência da Escola Normal foi decisiva na formação de um conjunto de práticas e possibilidades teóricas ${ }^{9}$ (CERTEAU, 2006 , p. 65) para que a ideia de um nacionalismo republicano estabelecesse sua tradição no cenário regional. Isso porque, efetivamente, para que pudessem circular nas escolas, os manuais, os compêndios e as cartilhas eram textos que precisavam ser aprovados pelos membros institucionais. As editoras nacionais se aproximavam dos letrados que a ela estavam vinculados, confirmando o prestígio da instituição e de seus professores.

O final do século XIX e os anos iniciais do século XX foram marcados, portanto, por um período em que os autores de livros escolares para a escola primária eram letrados que, por sua formação intelectual, produziam saberes escolares sem as características, ainda, de um campo disciplinar formado, mas em formação. As disputas e as divergências sobre a importância dos conteúdos a serem ensinados estavam presentes, mas, ao mesmo tempo, os letrados produziam para um público cada vez mais heterogêneo, não limitado mais aos filhos dos grandes proprietários rurais ou comerciantes. Tratava-se, isso sim, de um público escolar diferenciado, composto por alunos de ensino elementar com idades variáveis, o que impulsionava parte da elite intelectual ${ }^{10}$ pensar o "ser paranaense" dentro de um contexto maior, que era o "ser brasileiro". Por intermédio da imprensa, dos escritos dos letrados locais e da instituição escolar, a memória e a identidade paranaense foram sendo criadas por meio de

9 No texto A escrita da história, Certeau considera que o fazer teórico e prático está determinado pelo lugar "de onde falo e do domínio em que realizo uma investigação", sendo o lugar sua marca é indelével (CERTEAU, 2006, p. 65).

10 Sobre a formação da elite paranaense, ver Oliveira (2001). 
diversos mecanismos para propagar a identidade regional por eles construída.

Sebastião Paraná compreendia que, ao se servir dos saberes históricos, não só localizaria as raízes de uma identidade nacional, mas, também, encontraria as tradições de uma região que deveria seguir na "vanguarda modernista". Para tanto, pareceu-lhe imprescindível buscar amparo na geografia e na etnografia para traçar as fronteiras do território regional e inventálo historicamente, na conjuntura de um tempo em que se buscava definir progresso e modernização para o país.

\section{Progresso e modernização na narrativa de Sebastião Paraná: as figurações da história regional}

Representante de um diminuto grupo, os homens de letras, Sebastião empenhou-se em elaborar conhecimentos sobre o Brasil e sobre o Paraná, animado por um desejo de anunciar a grandiosidade de uma nação que, depois de um longo período monárquico, tornava-se republicana. A descrição do espaço paranaense por meio de sua formação geográfica e conteúdo territorial manifestava a vontade coletiva das elites locais em celebrar a possibilidade de difundir uma "identidade" grandiosa do território paranaense.

A reorganização do espaço estava associada, frente às transformações na vida econômica e política do país nos anos iniciais da República brasileira, a modos específicos de ver e de construir a realidade social. Como já apontou Gilberto Velho (1995), ao se realizar por intermédio de novas visões do tempo, espaço e indivíduos, a reorganização do espaço promove a luta teórica por definir tais conceitos. Nesse aspecto, como já é conhecida pela historiografia, a invenção histórica do Paraná, que inaugura um discurso de região no cenário republicano, inicia-se com a separação política de São Paulo, em 29 de agosto de 1853, para tornar-se província.

$\mathrm{Na}$ série de acontecimentos que conduziu à emancipação 
política do Paraná, Sebastião valorizou o dia 19 de dezembro de 1853, como ato fundador. Para ele, com a posse do presidente da província, Zacarias de Góes e Vasconcellos, é que se "[...] assignala a nossa entrada triumphal nos parametros do progresso e da civilização". (PARANÁ, 1929, p. 96). No escrito, foi a partir de 1853 que "começou o progresso da terra paranaense, a que estão reservados grandes destinos. Plaga predestinada, escolhida para centro da actividade de uma população numerosa e trabalhadora". (PARANÁ, 1929, p. 96).

Em seu texto, a força simbólica ${ }^{11}$ do marco de origem ${ }^{12}$ define as fronteiras e demarca o território na representação de região construída para o estado. Qualificar o espaço e oferecer um quadro geral descritivo do território conhecido e a conhecer e, ao mesmo tempo, difundir os conhecimentos "civilizadores" da ciência moderna, tornou-se o esforço empreendido por Sebastião Paraná ao conceituar a região no manual.

Limites e linhas divisórias, superfície, potamographia, colpographia, nesographia, riqueza natural, industria agricula, industria pastoril, industria fabril, industria extrativa, governo do Estado, divisão administrativa, representação federal, força publica, instrução popular, população, vias de comunicação, vias férreas, cidades, vilas são os temas que compõem a representação espacial e histórica do estado, no livro. Nele, a urbanização tornouse o objetivo dessas mudanças e o palco de desenvolvimento do Paraná, resultando no progresso científico e social movido por meio da ação política dos "ilustres homens" paranaenses.

11 Esse conceito se relaciona com o que Bourdieu denominou de "poder simbólico", que é "o poder de constituir o dado pela enunciação, de fazer ver e fazer crer, de confirmar ou de transformar a visão do mundo e, deste modo, a ação sobre o mundo." (BOURDIEU, 1989, p. 14).

12 O conceito se aproxima da ideia de "mito de origem". Marilena Chauí (2000) trata deste conceito e esclarece que o mito, neste caso, não é só no sentido etimológico, de narração de acontecimentos lendários, "mas também no sentido antropológico, de solução imaginária para tensões; fundador por trazer um vínculo com um passado de origem, do qual não há nunca desvinculação". (CHAUÍ, 2000). No caso deste trabalho, utiliza-se "marco" para reafirmar a importância historiográfica da questão. 
Uma vez criado o espaço político, caberia aos homens ilustrados dar voz ao estado, de modo a fazê-lo presente nos debates da época entre as grandes capitais, como convinha a uma nação civilizada. Por esse discurso, a figura do paranaense é representada, fundamentalmente, pelo homem culto e laborioso, fruto dos colonos audazes, capazes de vencer a natureza bruta, adentrar as matas "virgens", os rios encachoeirados, apropriar-se dos espaços "vazios" tomando posse do território para produzir riquezas.

No manual, a determinação geográfica possibilitaria conhecer - Paraná e sua história. Os rios receberam, nesse enredo, importância na identificação dos limites, margens e fronteiras, além de indicar o papel desempenhado pelos portos para o desenvolvimento comercial da região. Os rios foram vistos como as vias naturais fixas que levavam aos limites territoriais, permitiam o conhecimento do espaço e, ao mesmo tempo, o avanço do comércio. As referências aos roteiros navegáveis estão sempre ligadas com o possível trânsito de mercadorias locais.

A barra de Guatauba acha-se balisada, podendo entrar nella navios sem que haja receio dos perigos a que estavam sujeitos antes de se effectuar esse importante melhoramento. É assignalada por um pharol, assim como a de Paranaguá, indicada pelo pharol do morro das Conchas, na extremidade oriental da ilha do Mel. (PARANÁ, 1929, p. 104).

Tornar as águas navegáveis, ampliar os contatos regionais e nacionais fazia parte das melhorias que o governo, portanto, deveria realizar para compor o cenário nacional de grandiosidade na tarefa de civilizar o território.

Na sua narrativa, o espaço é território natural, a ser ocupado e explorado cientificamente, de forma que a presença dos nativos não está relacionada à utilização que faziam desses lugares, mas à sua existência como componentes da paisagem natural. No item "Nesographia", encontra-se a seguinte menção aos índios: 
Nesses sambaquis [colinas, formadas de grande quantidade de cascas de crustáceos e molluscos], tambem vulgarmente chamados ostreiras, teem se encontrado ossos humanos, cinzas, carvão vegetal, fragmentos de louça de barro, espinhas de peixes, machados de pedra e outros utensílios de que se utilizavam os primeiros habitantes daquelles logares. (PARANÁ, 1929, p. 105).

Somente poucos comentários aparecem para fazer referência à presença de índios na região, normalmente caracterizada como um acontecimento que se realizou no passado. Os espaços retratados como se estivessem vazios induzem à interpretação de que a história desses rios, com sua utilização e sua transformação humana, principia com a chegada do colono. Por isso, os índios são vistos como componentes da natureza, sem protagonizar suas histórias, na medida em que o ato fundador da História Regional foi a transformação do espaço pelo agente civilizador. Com um discurso voltado para a ocupação territorial, como se vê ao destacar o que se considerava riqueza natural, o autor afirma:

O Paraná, Estado novo, de terras fertilíssimas e clima delicioso; Estado onde não existem preconceitos de raças e de seitas; Estado que dá generoso acolhimento aos extrangeiros, de cujo concurso precisa para a sua prosperidade material, possui grandes e admiráveis riquezas naturaes. É uma enorme officina aberta ao trabalho, a todas as especulações industriaes. (PARANÁ, 1929, p. 106).

O núcleo da intenção de Sebastião com estes temas (terras férteis, clima propício, povo sem preconceito), para explicar as características da região, vinculou-se à preocupação em recuperar aspectos "promissores" do território e da política local, no que se refere ao seu desenvolvimento comercial, às relações de trabalho e à vivência social. Pressupunha o interesse em uma nova forma de representar o território, vinculada à ideia de progresso e de modernização. O que se mostraria na capacidade do estado de instaurar novas regras e normas sociais fundamentadas 
nos signos da modernidade científica como, por exemplo, na capacidade dos colonos e imigrantes para alterar o ambiente natural e as estruturas sociais com inovações tecnológicas na produção industrial.

Sebastião Paraná, ao tratar com os sentidos de região e história, construídos nos lugares institucionais aos quais se vinculava, produziu conhecimentos que, em geral, contrastam o espaço urbano com o campo ou o meio rural, objetivando caracterizar o que significava a "modernização" da sociedade. No esforço em apresentar como a situação geográfica paranaense estava adequada ao desenvolvimento da indústria e do comércio no estado, o autor destacou os produtos vegetais que se encontravam nas suas terras. No excerto abaixo, o pinheiro aparece como uma das madeiras que abundavam na região:

O reino vegetal é riquíssimo de madeiras excellentes para construcção civil e naval e para fabricação de objectos de marcenaria. Entre as madeiras mais estimadas que o Estado possue em grande cópia, destacam-se a imbuia, o angico, o taruman, o jacarandá, o Angelim, o carvalho, a cajarãna, a cabreuva, o ipê, o jequitibá, o guaraperê, o balsamo, o jatahy, o cedro, o pinheiro, uma das mais abundantes. (PARANÁ, 1929, p. 106).

Sobre esse cenário, Sebastião afirma, ainda, que o café também era promissor:

[...] está se desenvolvendo animadoramente no Paraná. Já existe notável plantação de café nos municípios do norte do Estado; canna de assucar, algodão, fumo, mandioca, arroz, milho, feijão, centeio, batata. Cebola, banana, uva, laranja e outras fructas. A exportação de banana para o Estado do Prata augmenta dia a dia e é feita pelos municípios do litoral, com excepção do de Guaratupa, que não dispõe de meios fáceis de transporte. (PARANÁ, 1929, p. 107-108).

Entre a madeira e o café, o mate é marcado como o impulsionador da vida econômica no estado, por tornar-se principal produto ali desenvolvido na indústria extrativa: 
A árvore do matte constitue o principal ramo da industria extractiva paranaense. Milhares de arrobas de hervamatte são annualmente exportadas, principalmente para Buenos Aires, Montevidéo e Valparaiso. Pode-se, pois, dizer que o Paraná assenta a sua riqueza em três grandes pedestaes: o matte, o pinheiro e o café. (PARANÁ, 1929, p. 107, grifo meu).

Esses três elementos constituíram-se no símbolo da riqueza natural paranaense presente no livro escolar. Enquanto, no contexto nacional, o principal produto era o café, no Paraná, o mate tratava-se de um "nicho econômico alternativo, que Ihes proporcionou uma atividade comercial intensa principalmente com o mercado platino [...]." (CORRÊA, 2006, p. 33). Para Sebastião Paraná, o progresso do comércio do mate seria determinante na tão sonhada "modernização" do estado e numa série de investimentos que, como se pensava, dariam origem ao desenvolvimento urbano e a uma ampla produção cultural nas suas principais cidades.

O mate, o pinheiro e o café tornaram-se os símbolos representativos da história do Paraná ${ }^{13}$, formando um discurso representativo na luta pela construção da identidade regional. De modo que, na construção de um discurso que definiu essa identidade, a abordagem econômica das elites tornou-se dominante, como nas outras regionalidades que também se construíam nesse contexto no cenário brasileiro:

É importante e consiste principalmente na extracção de pinho e de herva-matte, o mais valoroso producto da industria extractiva paranaense. Região nenhuma da America foi melhor aquinhoada de hervaes do que o Paraná. Na zona de Serra-Acima existem

13 Saint-Hilaire, naturalista francês que viajou pelo país no século XIX, 1822, já apontava em seus escritos que a natureza da região tinha sua síntese no Pinheiro do Paraná. Para ele, "o pinheiro era a planta que carcaterizava a região, não apenas por seu aspecto e intensidade de incidência da paisagem, mas pela importância de sua madeira e do fruto, o pinhão, para os habitantes dos Campos Gerais". (PEREIRA; IEGELSKI, 2002, p. 52). 
florestas nativas desta arvore preciosa do Brasil meridional, como o são no norte a carnaubeira, a seringueira e a mangabeira, que fornecem a cera e borracha. (PARANÁ, 1929, p. 110-111).

A ideia presente na narrativa é a de que o meio havia sido o principal elemento impulsionador da conquista paranaense do progresso, visando demonstrar a erva mate como o núcleo irradiador de tal conquista. Os elementos simbólicos se definiram, portanto, entre os produtos comerciais que eram dominantes nas terras paranaenses, dentre os quais, "é, pois, o matte o ramo preponderante da nossa industria, aquelle que até hoje tem attrahido maior soma de braços e capitaes" (PARANÁ, 1929, p.111).

$\mathrm{Na}$ busca por figurar um discurso de construção identitária, elegeu-se os elementos da produção agrícola, numa trama discursiva capaz de incorporar o imigrante ao tratar do trabalho, do cultivo da terra, nessa construção simbólica da identidade regional. Por isso, Sebastião, ao tratar das relações de trabalho, elaborou uma escrita que exaltava a "soma de braços" e a existência de um possível interesse da população pela atividade industrial e manufatureira:

Nesses pequenos centros de vida industrial, vê-se salutar a agitação agrícola que impressiona agradavelmente o espírito. Ahi se aprecia o esforço constante e sincero, o anhelo de progredir, a applicação ao trabalho quotidiano e a confiança no meio onde extrangeiros e seus descendentes labutam confiantes nos dias do porvir. (PARANÁ, 1929, p. 108).

A propensão da índole do homem paranaense ao trabalho é uma construção que acontece, no manual, quando o autor enaltece o imigrante e seus descendentes no desenvolvimento da vida industrial das cidades paranaenses. A visão republicana de progresso revestiu-se, pois, no Paraná, da defesa do trabalho livre e da urbanização, cuja noção precisava ser recuperada em decorrência de um passado rural e escravista. Nesse pressuposto, era fundamental para as elites identificar o trabalho livre com 
riqueza, uma vez que se explicariam os progressos alcançados também na atuação dos cidadãos laboriosos.

Nesse quesito, Sebastião Paraná esperava que os poderes políticos fossem as forças propulsoras dos recursos financeiros e mantenedores da ordem e do progresso social. Por isso, na continuidade de seu texto, o autor passa a tratar dos aspectos político-administrativos do estado. Descreve como o governo era exercido, como se dividia a administração e os municípios e sua representatividade junto ao governo da República. Na parte final do livro, trata especificamente dos temas: "força publica", "instrução popular"; "população", "vias de comunicação"; "vias férreas", "cidades", encerrando com "vilas".

O conceito de região, pensado como uma unidade de análise territorial e da organização administrativa do espaço físico, possibilitou localizar o "ponto zero" (HOBSBAWN; RANGER, 1984) que pudesse fazer com que os leitores do manual se identificassem num passado comum. Nesse sentido, no livro de Sebastião Paraná, geografia e história se relacionaram para inventar o território e as tradições paranaenses. Pensada como saber escolar, a geografia explicaria a identidade regional por intermédio dos seus atributos naturais e dos produtos agrícolas centrais, assim como a historiografia se tornaria um dos instrumentos legitimadores de tal construção, identificando a formação das vilas, a força do trabalho e o desenvolvimento dos núcleos urbanos por meio das primeiras famílias colonizadoras ali situadas.

\section{Considerações finais}

Apresenta-se neste artigo, um estudo sobre o livro didático na perspectiva da História das Disciplinas, a partir da qual se apresenta o manual escolar do intelectual paranaense Sebastião Paraná. Na análise, observou-se que o autor, ao tratar do Brasil e do Paraná, tornou o território um emblema da nação. Através das suas linhas e do traçado das suas fronteiras, fez surgir a 
região como um espaço pertencente ao território nacional. Aqui reside um aspecto central trazido pelo artigo: reconhecer como o conceito de região figurou nos livros escolares para a escola primária nos anos iniciais da República paranaense.

Nesse aspecto, o livro de Sebastião Paraná divulga um conceito de região tendo o território nacional e sua natureza como paradigma para se conhecer o que era o Brasil e estabelecer diagnósticos sobre os seus problemas para adentrar o conjunto das nações civilizadas. No horizonte da construção desse conceito estava o desejo das elites assentadas no poder de civilizar, ou seja, de ocupar o território, de explorar a natureza, de urbanizar o espaço conhecido e a conhecer.

Com o propósito de legitimar as fronteiras conquistadas pelo estado, o manual é representativo - pelos elogios que recebeu, pela premiação conquistada e pelas reimpressões recebidas de um projeto educativo que destaca as especificidades de uma região e suas respectivas contribuições para a grandeza da nação, como vistas à construção de um passado de tradições comuns. Da história, se esperava entender a unidade nacional e, da geografia, o desenvolvimento da região, numa mesma temporalidade e progressão criada para explicar a história nacional.

A divisão hierárquica de Brasil e Paraná, ou nação e região, presente no livro, implicou a definição de uma "História Regional" e sua relação com a história nacional no decorrer do século passado. Tal definição - região como subsistema do nacional ainda está presente nos livros didáticos atuais, cuja narrativa tem por base o recorte político-administrativo e econômico. Narrativa que se torna hegemônica no ensino escolar e excludente de outras memórias, de outros grupos sociais.

O principal intento do artigo foi enfatizar, portanto, a construção que Sebastião Paraná fez sobre o universo simbólico da identidade regional baseada nos três elementos que formaram as atividades econômicas da elite regional: o mate, o pinheiro e o café. A geografia da região foi simbolicamente representada, enfim, através do "espírito empreendedor" existente entre o grupo ervateiro, representante das elites dominantes paranaenses 
no início do século XX. A visão de modernidade e progresso, construída e presente no manual escolar, incorporou, desse modo, uma representação específica das elites políticas e econômicas dominantes do final do século XIX e anos iniciais do século $X X$.

Em outras palavras, nos recantos privilegiados das elites paranaenses, o peso da formação econômica na narrativa sobre a memória e a identidade regional representa o esforço exercido por essas elites na tarefa de criar o estado, discursiva e simbolicamente, à sua semelhança. Por seu intermédio, construiuse a ideia de região, de identidade e se posicionou a história regional como anexa à história nacional nas décadas iniciais do século XX. E, ao mesmo tempo, marcou-se a definição do campo disciplinar da História e da Geografia como disciplina escolar, no contexto de uma vontade de atores históricos específicos - os letrados - em celebrar a possibilidade de difundir uma "identidade grandiosa" do território paranaense. Sebastião Paraná, por meio de seu manual, contribuiu decisivamente para a construção dessa memória do estado que é ensinada nas escolas de ensino fundamental do Paraná até hoje.

\section{Referências bibliográficas}

BITTENCOURT, Circe M. Fernandes. Autores e editores de compêndios e livros de leitura (1810-1910). Educação e Pesquisa. São Paulo, v. 30, n. 3, p. 475-491, set./dez. 2004.

BOLETIM. Instituto Histórico e Geográfico Paranaense. Curitiba: Imprensa Paranaense, 1917.

BOURDIEU, Pierre. Sobre o poder simbólico. In: O poder simbólico. Lisboa, Difel, 1989. p. 7-16.

BOGUSZEWSKI, José Humberto. Uma história cultural da erva-mate: o alimento e suas representações. 2007. 130 f. Dissertação (Mestrado em História) - Programa de Pós-Graduação em História, Universidade Federal do Paraná, Curitiba, 2007. 
CERTEAU, M. A escrita da história. 2. ed. Rio de Janeiro: Forense Universitária, 2006.

CHAUÍ, Marilena. Brasil: Mito fundador e sociedade autoritária. São Paulo: Fundação Perseu Abramo, 2000.

CHARTIER, Roger. A história cultural: entre práticas e representações. Lisboa: Difel, 1990.

CHERVEL, Andre. História das disciplinas escolares: reflexões sobre um campo de pesquisa. Teoria \& Educação. n. 2, p. 177-229, 1990.

CORRÊA, Amélia. S. Imprensa e política no Paraná: prosopografia dos redatores e pensamento republicano no final do século XIX. 2006. 230 f. Dissertação (Mestrado em História) - Programa de Pós-Graduação em Sociologia, Universidade Federal do Paraná, Curitiba, 2006.

GUIMARÃES, Manoel Salgado. Nação e civilização nos trópicos: o Instituto Histórico e Geográfico Brasileiro e o projeto de uma História Nacional. Estudos Históricos, Rio de Janeiro, v. 1, p. 5-27, 1988.

HOBSBAWM, Eric; RANGER, Terence (Orgs.). Invenção das tradições. Rio de Janeiro: Paz e Terra, 1984.

LAJOLO, Marisa. Livro didático: um (quase) manual de usuário. Em Aberto, Brasília, n. 69, p. 3-9, jan./mar. 1996.

LE GOFF, Jacques. História e memória. Campinas, SP: Ed. Unicamp, 1996.

MARTINS, Romário. História do Paraná. Curitiba: Travessa dos Editores, 1995.

NORA, P. Entre memória e história. A problemática dos lugares. Projeto História, São Paulo, n. 10., p. 7-28, dez. 1993.

OLIVEIRA, Ricardo Costa de. O silêncio dos vencedores: genealogia, classe dominante e estado no Paraná. Curitiba: Moinho do Verbo, 2001.

PARANÁ, Sebastião. O Brasil e o Paraná: para uso das escolas primárias. 19. ed. melhorada. Curitiba: Empreza Graphica Paranaense, 1929.

PEREIRA, Marco A.M; IEGELSKI, Francine. O paraíso terrestre no Brasil: 
os Campos Gerais do Paraná no relato de Auguste de Saint-Hilaire. Revista de História Regional, Ponta Grossa, v. 7, n. 1, p. 47-72, 2002. TOLEDO, Maria Aparecida Leopoldino T. A disciplina de História no Paraná: os compêndios de História e a história ensinada (1876-1905). 2005. 170 f. Tese (Doutorado em Educação) - Programa de Estudos Pós-Graduados em Educação: História, Política Sociedade, Pontifícia Universidade Católica de São Paulo, São Paulo, 2005.

VELHO, Gilberto. Estilo de vida urbano e modernidade. Estudos Históricos, Rio de Janeiro, v. 8, n. 16, p. 227-234, 1995.

Recebido em junho de 2016. Aprovado em junho de 2017. 